\title{
Effect of Financial Literacy on Individual Savings Behavior; the Mediation Role of Intention to Saving
}

\author{
T. U. I. Peiris
}

\section{ABSTRACT}

\begin{abstract}
This study investigated the effect of financial literacy on savings behavior, considering the mediation effect of intention to savings. A structured questionnaire was distributed among 206 employed individuals in the Colombo district, Sri Lanka. Three Stage Least Squares technique was initially used to analyze the structural equations model fitted to measure the hypothesized mediation effect. Then the result was rousted using path analysis. The findings indicated that financial literacy has a direct and positively significant influence on savings behavior. Moreover, the mediation effect of intention was also found as positively significant in the above relationship. This indicates that the knowledge of the financial system leads to good savings behavior, and especially it creates an intention to save more. Therefore, policymakers and financial institutions can consider enhancing financial literature among individuals as a worthy strategy when encouraging savings as it both encourages savings behavior and the intention to do so.
\end{abstract}

Keywords: Financial Literacy, Intention to Savings, Mediation Effect, Savings Behavior, Structural Equations Model.
Submitted : August 19, 2021

Published : September 12, 2021

ISSN: 2507-1076

DOI: $10.24018 /$ ejbmr.2021.6.5.1064

\section{T. U. I. Peiris*}

Department of Accountancy and Finance, Faculty of Management Studies, Sabaragamuwa University of Sri Lanka, Sri Lanka.

(Email: ushan@mgt.sab.ac.lk)

*Corresponding Author

\section{INTRODUCTION}

The role of financial literacy in various aspects of economic and household wellbeing has been investigated through numerous academic studies. [1]-[3] have pointed out that financial literacy has severe implications for wealth accumulation and portfolio choice. Similarly, several other researchers have shown that financial literacy has an effect on the level of participation in the formal financial market and stock market [4]-[6]. Moreover, lack of financial literacy would lead to so many adverse effects as well. For example, according to [7]-[10] it may result in costly borrowing and a high debt load. All in all, financial literacy has implications for savings, investments, stock market participation and significantly determines the financial and economic development of an economy [11].

Among the studies that concentrated on the relationship between financial literacy and macroeconomic factors, studies investigating the impact of financial literacy on savings are widely available for several reasons. According to [12], savings have a significant positive effect on the economy because funds placed in financial assets are then channeled through banks and other financial intermediaries to fund investments by firms. Subsequently, investments by firms will ultimately benefit the nation through higher productivity and economic growth. Furthermore, high savings can also hedge countries against economic downturns and financial crises. Realizing its importance, policymakers take so many strategies to boost savings in an economy. Among them, programs to enhance individuals' financial literacy are widespread because they heighten understanding of their financial circumstances, enable them to make financial plans for the future, and choose the most appropriate financial instrument to help them achieve their financial goals [12].

On this background, many studies hypothesized that higher levels of financial literacy positively impact individuals' savings because, with a better understanding of financial circumstances, individuals make more informed financial decisions. However, this hypothesis might not be valid most of the time because knowledge is not the only determinant of individuals' behavior. Therefore, recent studies that concentrated on the relationship between financial literacy and savings have taken variables like attitude, subjective norms, and perceived behavior as control variables. This study further extends the above argument emphasizing the role of intention to savings in this regard. Theoretically, intention mediates the broad relationship between knowledge and behavior, which is hardly tested in the context of financial literacy and savings. Thus, this study investigates the mediation role of intention to savings in the relationship between financial literacy and savings.

\section{LITERATURE REVIEW}

Theory of Planned Behavior (TPB) is one of the widely used theories when studying human behaviors. According to [13], TPB offers an excellent conceptual basis for research in dealing with the complexities of human social behavior. Further, it has also been used very often to clarify the behavioral pattern and better recognize how individuals make behavioral choices [14]. Reference [15] reported that TPB is also used to examine the more profound opinions that affect an individual's financial behavior. Reference [16] also stated 
that the TPB has been adapted repeatedly in the literature of social psychology and has been applied to experiments in the domestic and international fields of credit counseling, personal finance, and private money management.

TPB is based on three distinct factors of Attitude (AT), subjective norms (SN), and perceived behavioral control (PBC) that cause to have an intention to do something, which leads to occur a particular behavior [13]. The Attitude towards behavior means a person's viewpoint regarding actions, which can be beneficial or unwanted. It also refers to a particular way to think about something or experience something [17]. According to [16], saving attitudes should be strictly connected and embedded with education and lifestyle. By collaborating that, [18] indicated that most people have positive attitudes toward saving.

On the other hand, an incentive to adhere to the views of others is a significant factor that determines human behavior, which is recognized within the TPB as subjective norms (SN). This means that opinions of friends, family members, neighbors, or any human being essential to a person's life may influence his intention and behavior. Meanwhile, the perceived behavioral control (PBC) is the belief by an individual regarding the easiness or difficulty in undertaking certain behaviors. This means that the stronger the PBC of a person, the more likely they are to depict the hypothesized behave [13]. Previous studies have shown a strong and positive relationship between $\mathrm{PBC}$ and behavioral intention [19].

The intention is also a basic foundation of the TPB and will directly impact a specific activity since it is an indicator of how eager individuals are to perform a particular action [20]. Further, [21] also stated that behavioral intention is a phase that may lead to action, and they have found that intention to saving is significantly influenced by actual saving behavior. Considering the validity of the TPB as a basis for explaining human behaviors, many researchers used it to examine the relationship between financial literacy and individual saving behavior.

Reference [22] indicated that financial literacy influences the financial decision-making of individuals. Similarly, a positive relationship between financial literacy and the saving behavior of individuals has been identified by [23], and it was a strong relationship than the other factors affecting the saving behavior. Reference [24], using a sample of 420 students of public universities in Malaysia, investigated the saving behavior by applying the TPB. In this study, they have found that financial literacy, parental socialization, peer influence, and self-control positively impact saving behavior. In contrast, parental socialization had a more significant impact on saving behavior since parents play an essential role in children's lives. Reference [25] also used TPB to examine the impact of financial literacy on teachers' saving intention and saving behavior in Indonesia. According to the results, an insignificant relationship between financial literacy and Attitude towards saving and saving intention has been confirmed. Further, Attitude and subjective norms also have significantly influenced saving intention. Subsequently, [17] has conducted a research study with the employees of the University of Botswana based on the TPB to identify behavioral intention and potential policy strategies for a retirement fund for those employees. According to the result, it has been found there are positive effects of Subjective norms, financial literacy, and Attitude on intention to make contributions to retirement savings. In addition, it has been found that Attitude mediates the relationship between subjective norms and retirement saving intention, and also it mediates the relationship between financial literacy and retirement savings intention. Later, [16] found that Attitude, subjective norms, and perceived behavioral control directly affect intention towards saving and final saving behavior.

Similarly, [26] examined the effect of financial literacy on personal savings considering Usak University staff. They found that financial literacy, income level, age, and level of education positively influenced personal savings, while risk tolerance negatively impacted personal savings. The Decomposed Theory of Planned Behavior (DTPB) has used [27] to examine the intention to save involuntary retirement funds in Malaysia from a sample of 334. The results have identified a significant effect from Attitude, subjective norms, and perceived behavioral control on persons' intention to save. With the aim of determining the factors that influence saving behavior, a research study was conducted by [28]. As a result, he recognized five determinants: quality of services, religious belief, knowledge, social influences, and media advertisements as some of the significant determinants of saving behavior. Recently, [29] examined the degree and effect of financial literacy on savings and spending behavior from 72 respondents in the Royal Institute of Management, and the results indicated that the degree of financial literacy is influenced by the level of income rather than by age, gender, and marital status. Further, a researcher reported that high-income participants have high educational qualifications and had a higher level of financial literacy than others, as predicted.

In summary, it is evident that many researchers, who used the TPB as a basis to investigate the relationship between financial literacy and savings behavior of the individuals, have examined the direct relationship between the components of TPB that applies to financial literacy and the savings behavior. However, the role that intention to savings could play in between financial literacy and savings behavior is hardly investigated. Thus, this study investigates the mediation role of intention to savings in the relationship between financial literacy and savings.

\section{Methodology}

\section{A. Hypothesis Development}

Many researchers have suggested that financial literacy is a crucial determinant of individual saving behavior [21]. According to [26], financial literacy simulates individuals and households to have good spending habits and to promote savings. Reference [30] stated that those with the highest awareness might go for sound investments and attain their financial goals. Therefore, a direct relationship between financial literacy and the savings behavior can be hypothesized;

$H_{1}$ : There is a direct positive relationship between financial literacy and individual saving behavior. 
The intention to saving, which is a core construct of TPB, can be considered a mediating factor that influences the relationship between financial literacy and individual saving behavior. Reference [31] stated that the higher the intention to perform a specific behavior, the greater the probability of the behavior would take place. Hence following hypotheses can be constructed:

$\mathrm{H}_{2}$ : The intention to saving mediates the relationship between financial literacy and individual saving behavior.

Fig. 1 depicts the conceptual framework of the study in which intention to savings is taken as a mediating variable in the relationship between financial literacy and savings behaviour.

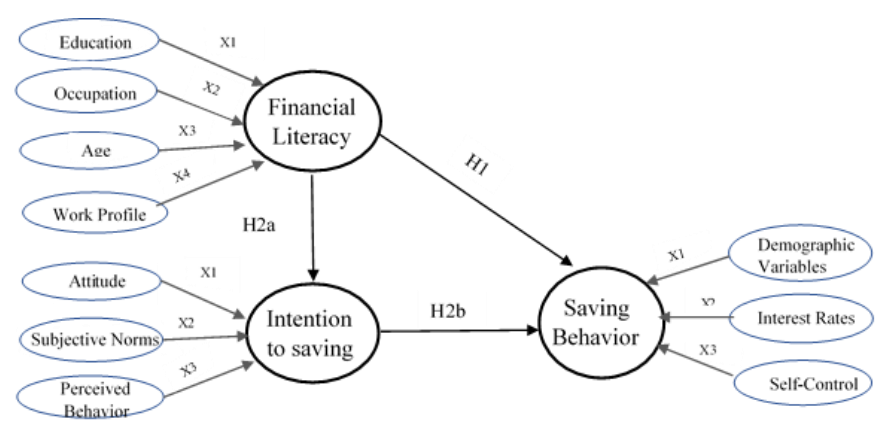

Fig. 1. Conceptual Framework.

\section{B. The Sample and Data}

The target population of this study was the employed individuals from both government and private sectors and living in the western province, Sri Lanka. Since the population is unknown, the sample size is calculated using a sample size calculator, and according to that, when the population is unknown and under the $95 \%$ confidence level, theoretically, the sample size should be 385 respondents. A self-administered structured questionnaire is used in order to collect the required data from sample respondents, which are distributed online. However, due to the prevailed situation in the country under the Covid-19 pandemic, the researcher could collect data only from 206 respondents.

This study is expected to investigate any mediating effect from intention to saving on the relationship between financial literacy and individual saving behavior. Therefore, Structural Equations Modeling (SEM) technique is used to model the relationships hypothesized in this study. SEM is a statistical technique that combines multivariate techniques such as regression, factor analysis, path analysis, and simultaneous equations into a single model fitting structure. The use of SEM has become prevalent across research fields that analyze the complex theories related to social science issues that cannot be directly observed, which is also applicable to this research.

\section{Model Development}

Concerning the objectives and developed research hypotheses, firstly, it is expected to investigate whether there is a direct relationship between financial literacy and individual saving behavior. At the same time, the researcher has identified the determinants of individual saving behavior that have been commonly used in the empirical literature. The model for the saving behavior is as follows.
$S B_{i}=\beta_{0}+\beta_{2} I n t S_{i}+\beta_{1} F L_{i}+\beta_{3} D v_{i}+\beta_{4} I R_{i}+\beta_{5} S f C_{i}+$ $\varepsilon_{i}$

where, $S B_{i}$ indicates the saving behavior of person $i . D v_{i}$ indicates demographic variables of person $i . S f C_{i}$ refers to self-control of person $i$, and $I n t S_{i}$ refers to intention to saving of person $i . \varepsilon_{i}$ is the error term.

Next, the researcher expects to examine the mediating effect of intention to saving on the relationship between financial literacy and individual saving behavior. The model specification for the mediation equation is as follows;

$I n t S_{i}=\gamma_{0}+\gamma_{1} F L_{i}+\gamma_{2} A t d_{i}+\gamma_{3} S N_{i}+\gamma_{4} P B_{i}+\varepsilon_{\varepsilon}(2)$

where, $\operatorname{Int} S_{i}$ indicates the intention to saving of person $i . F L_{i}$ refers to financial literacy of person $i$. $A t d_{i}$ indicates the attitude towards saving of person $i . S N_{i}$ refers to subjective norms of person $i$ while $P B_{i}$ indicates the perceived behavior of person $i$ and $\varepsilon_{i}^{I n t S}$ is the error term.

\section{Estimation of the Structural Parameters}

Structural estimation modeling is a method for estimating the theoretical economic models with deep "structural" parameters. The 3-stage least squares (3SLS) estimator, which blends two-stage least square (2SLS) properties with seemingly unrelated regression (SUR) estimators, is used as the primary analysis tool of the study, while path analysis is used as the Robusting analysis tool. The statistical significance of the mediation relationship was tested by using the Sobal test.

\section{DATA ANALYSIS AND DISCUSSION}

\section{A. Reliability Analysis}

The reliability of the data collection instrument was tested by using Cronbach's alpha, which is usually applied to check the accuracy of the measurements that ensures measurements are free from bias to get valid and accurate results. A score above 0.7 for a Cronbach's alpha is an indication of adequate reliability. After the pilot study, the reliability test was done, and only the constructs with a Cronbach's alpha value above 0.7 were used to collect the data. Below Table 1 shows Cronbach's alpha values for all the measurements used in the study.

\begin{tabular}{ccc}
\multicolumn{3}{c}{ TABLE I: TEST OF RELIABILITY } \\
\hline Construct & $\begin{array}{c}\text { Number of } \\
\text { items }\end{array}$ & $\begin{array}{c}\text { Cronbach's } \\
\text { alpha }\end{array}$ \\
\hline Saving Behavior (SB) & 21 & 0.749 \\
Financial literacy (FL) & 09 & 0.717 \\
Intention to Saving (INTS) & 23 & 0.829 \\
\hline
\end{tabular}

\section{B. Measuring the Structural Relationship}

Table II shows the coefficient estimates for the structural model. Results indicate that in the saving behavior model (SB), the P-value of the FL is 0.009 , which is less than 0.05 . Therefore, FL is statistically significant at $95 \%$ confidence level. This indicated that FL significantly influences the savings behavior of the individuals. Moreover, results provide a positive coefficient for FL, indicating a positive relationship between financial literacy and individual saving 
behavior in Sri Lanka. In addition to that, the mediating variable, intention to saving (IntS), also got significant in the SB model as the P-value (0.045) is less than 0.05. Results further indicate that out of three control variables considered, only the coefficient of interest rates (IR) was found statistically significant at $95 \%$ confidence level.

In the intention to savings model, only the perceived behavior and financial literacy got significant, while attitude for saving and subjective norms are not statistically significant at $95 \%$ confidence level. Also, the coefficients for perceived behavior and financial literacy show positive values. This indicates that both perceived behavior and financial literacy have a positive relationship with the intention to savings. However, attitude for saving and subjective norms do not significantly influence the intention to saving in the Sri Lankan context.

\section{Measuring the Mediating Effect}

The Sobal test was used to calculate the mediating coefficient's standard error, thereby obtaining the $t-$ value for the mediation effect. The reported results indicate that intention to saving (INTS) positively influences the Saving Behavior (SB) as the coefficient value is 0.289 . In contrast, the effect of Financial Literacy (FL) on intention to saving (INTS) is also a positive one representing a coefficient value

of 0.170 . Therefore, the mediation effect of Financial Literacy is represented by the coefficient value of 0.04913 $(0.289 * 0.170)$. When considering the statistical significance at $95 \%$ confidence level, the $\mathrm{t}$-value for the mediation effect is 2.385 , which is more than value 2 . Therefore, the study results indicate that intention to savings positively and significantly mediates the relationship between Financial Literacy and Saving Behavior.

TABLE II: COEFFICIENT ESTIMATES FOR THE STRUCTURAL MODEL

\begin{tabular}{ccc}
\hline & \multicolumn{2}{c}{ Three-Stage Least Squares } \\
\cline { 2 - 3 } & Saving Behavior & Intention to Saving \\
\hline Constant & -0.8782895 & $1.34 \mathrm{e}-06$ \\
FL & $0.2381081^{*}$ & $0.170112 *$ \\
IntS & $0.2898127^{* *}$ & - \\
IR & $-0.1605988^{* *}$ & - \\
SFC & -0.0067244 & - \\
Gender & -0.0735446 & - \\
Age & 0.17927 & - \\
Education & 0.066728 & - \\
Occupation & 0.0536023 & - \\
Marital_status & 0.2682551 & - \\
Income & -0.0518446 & - \\
Work_Profile & -0.0433744 & -0.0238653 \\
ATD & - & -0.0238653 \\
SN & - & $0.704179 *$ \\
PB & - &
\end{tabular}

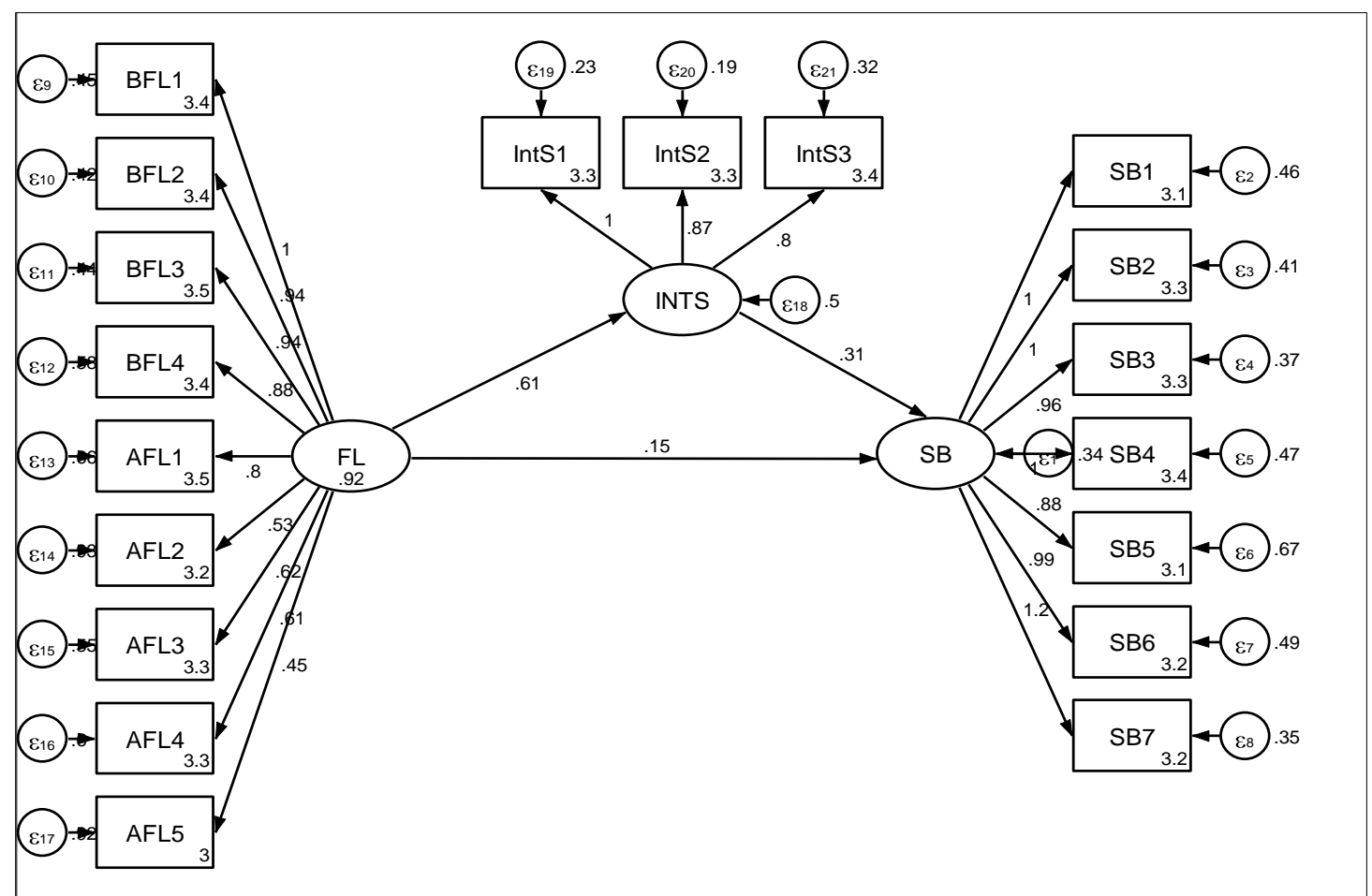

Fig. 2. Path analysis.

\section{Path Analysis}

In order to provide an additional confirmation on the result that generated using three-stage least squares (3SLS) estimator, the SEM path diagram was built for mediation analysis using the latent and the construct variables of the study.

Factor loading is a significant indicator for ensuring the validity of the model. Validity of the constructs has occurred if the factor loadings are significant and above 0.5. As per Fig. 2, all the latent variables have factor loading above the threshold mark of 0.5 , indicating that validity is supported. The direct relationship between the construct variables obtained through the path analysis is reported in Table III.

\begin{tabular}{|c|c|c|c|}
\hline Path & $\begin{array}{c}\text { Substandard } \\
\text { Regression Weights }\end{array}$ & P-Value & Result \\
\hline 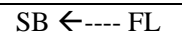 & 0.148 & 0.033 & Significant \\
\hline INTS $\leftarrow---$ FL & 0.612 & 0.000 & Significant \\
\hline SB $\leftarrow----$ INTS & 0.305 & 0.000 & Significant \\
\hline
\end{tabular}


The reported results in Table III indicate a statistically significant relationship between these variables, further confirming the results obtained for the 3-SLS model. The direct effect of financial literacy on savings behavior is positive (0.148) and statistically significant at 95\% confidence level as the p-value is 0.033 . Similarly, the effect of financial literacy on intention to savings and the effect of intention to savings on savings behavior is positive and statistically significant. Thus, the mediation effect of intention to saving is also positive and statistically significant.

\section{CONCLUSION}

This study investigated the effect of financial literacy on savings behavior, considering the mediation effect of intention to savings obtaining a sample from the employed individuals living in the western province in Sri Lanka. The significant findings in this regard indicated that financial literacy has a direct and positively significant influence on savings behavior. Therefore, it confirms the recent findings of [29] and [32]. Moreover, the mediation effect of intention was also found as positively significant in the above relationship. This indicates that the knowledge of the financial system leads to good savings behavior, and especially it creates an intention to save more. An increasing saving rate will drive fast economic growth and therefore taking action to improve savings within an economy is vital as it ensures the personal well-being of the individuals and the economy as a whole. As reported in this study, enhancing the financial literacy among individuals would be a good strategy as it encourages savings behavior and the intention to do so. Therefore, authorities could implement policies to improve the financial literacy among the individuals and, in turn, can expect an improved savings behavior among the individuals. In addition, financial institutions also can pay more attention to improving individuals' saving intention by educating them about saving products and investment options.

\section{REFERENCES}

[1] Banks, James and Zoë Oldfield. Understanding pensions: cognitive function, numeracy and retirement saving. Fiscal Studies, 2007, 28 (February): 143- 70.

[2] McArdle, John J., James P. Smith, and Robert Willis. Cognition and Economic Outcomes in the Health and Retirement Survey. NBER Working Paper, No. 15266, 2009.

[3] Alessie, Rob, Annamaria Lusardi, and Maarten van Rooij. Financial Literacy, Retirement Planning, and Household Wealth. NBER Working Paper, No. 15350, 2008.

[4] Hogarth, Jeanne M., and Kevin H. O'Donnell.. Banking Relationships of Lower-income Families and the Governmental Trend toward Electronic Payment. Federal Reserve Bulletin, 1999, 86 (July): 459473.

[5] Christelis, Dimitris, Tullio Jappelli, and Mario Padula. Cognitive abilities and portfolio choice. European Economic Review, 2010, 54 (January): 18-39.

[6] Cole, Shawn, Thomas Sampson, and Bilal Zia. Money or knowledge? What drives the demand for financial services in developing countries? Harvard Business School Working Paper, No. 09-117, 2008.

[7] Lusardi, Annamaria A. and Peter Tufano. Debt Literacy, Financial Eexperiences, and Overindebtedness. NBER Working Paper, No. 14808, 2009
[8] Moore, Danna. Survey of Financial Literacy in Washington State: Knowledge, Behavior, Attitudes, and Experiences. SESRC Technical Report, No. 03-39. Washington State University, 2003.

[9] Stango, Victor, and Jonathan Zinman. Exponential Growth Bias and Household Finance. Journal of Finance 64 (December): 2807-2849, 2009.

[10] Campbell, John. Household Finance. Journal of Finance 61 (August): 1553-1604, 2006.

[11] Beck, Thorsten., Asli Demirgüç-Kunt, and Ross Levine. A new database on financial development and structure. Policy Research Working Paper Series, No. 2146, The World Bank, 2009.

[12] Mahdzan, N. S., \& Tabiani, S. The Impact of Financial Literacy on Individual Saving: An Exploratory Study in the Malaysian Context. Transformations in Business \& Economics, 2013, Vol. 12, No 1 (28), 44.

[13] Ajzen, I. Constructing a TPB Questionnaire: Conceptual and Methodological Considerations, 2006.

[14] Xiao, J. J., \& Wu, J. Completing debt management plans in credit counselling: An application of the theory of planned behaviour. Journal of Financial Planning and Counseling, 2008, 19(2), 29-45.

[15] Zocchi, P. Why do Italian households prefer adjustable rate mortgages? Journal of European Real Estate Research, 2013, 6(1),90-110.

[16] Satsios, N., \& Hadjidakis, S. Applying the Theory of Planned Behaviour (TPB) in Saving Behaviour of Pomak Households. International Journal of Financial Research, 2018, Vol. 9, No. 2, 122124.

[17] Mahlanza, T. J. Factors Influencing Retirement Savings Intentions in Botswana. Deakin University: Submitted in partial fulfilment of the requirements for the degree of Doctor of Business Administration (D.B.A), 2015.

[18] Yusof, R., Sabri, M. F., \& Rahim, H. A. Examining the behavioural intention to save in a voluntary retirement fund in Malaysia. Journal of consumer and family economics, 2018, VOL. 21, 78.

[19] Johnson, D. P. How Attitude Toward the Behavior, Subjective Norm, and Perceived Behavioral Control Affects Information Security Behavior Intention. Walden University, 2017.

[20] Armitage, C., \& Conner, M. Efficacy of the theory of planned behaviour: A meta analytic review. British Journal of Social Psychology, 2001, 40, 471-499.

[21] Widyastuti, U., Suhud, U., \& Sumiati, A. The Impact of Financial Literacy on Student Teachers' Saving Intention and Saving Behaviour. Mediterranean Journal of Social Sciences, 2016, 41-48.

[22] Brown, K. A. Examining the influence of financial literacy education on financial decision-making among graduate level health professions students. (Doctoral Dissertation Capella University), 2009.

[23] Amponsah, B. assessing the effect of financial literacy on saving behaviour: a case study of small scale miners in manso atwere in amansie west district. A thesis submitted to the Department of Accounting and Finance, KNUST School of Business, Kwame Nkrumah University of Science and Technology, Kumasi, in partial fulfillment of the requirement for the degree of Master of Business Administration, 2015.

[24] Thung, C. M., Kai, C. Y., Nie, F. S., Chiun, L. W., \& Tsen, T. C. Determinants of saving behaviour among the university students in malaysia. universiti tunku abdul rahman: A research project submitted in partial fulfillment of the requirement for the degree of Bachelor Of Commerce (HONS), 2012.

[25] Widyastuti, U., Suhud, U., \& Sumiati, A. The Impact of Financial Literacy on Student Teachers' Saving Intention and Saving Behaviour. Mediterranean Journal of Social Sciences, 2016, 41-48.

[26] Bayar, Y., \& Sasmaz, M. U. Impact of Financial Literacy on Personal Saving: A Research on Usak University Staff. Journal of Knowledge Management, Economics and Information Technology, 2018, 3.

[27] Yusof, R., Sabri, M. F., \& Rahim, H. A. Examining the behavioural intention to save in a voluntary retirement fund in Malaysia. Journal of consumer and family economics, 2018, Vol. 21, 78.

[28] Ismail, S. An Empirical Investigation on Determinants of Attitude towards Saving Behaviour. International Conference on Economics and Business Research (ICEBR), 2013, pp. 1-11.

[29] Wangmo, P. Assessing the Level and Impact of Financial Literacy on individualsaving and spending habits in Royal Institute of Management. Royal Institute of Management., 2019

[30] Pradeep, S., \& Nair, B. C. Perceived financial literacy and savings behavior of it professionals. International Journal of Mechanical Engineering and Technology, 2018, 948.

[31] Rickwood, C. M., Johnson, L. W., Worthington, S., \& White, L. Customer intention to save for retirement using a professional financial services planner. Financial Planning Research Journal, 2017, 47-67. 
European Journal of Business and Management Research www.ejbmr.org

[32] Kamarudin, Z. Factors affecting the saving behaviour of taj international college students. The Journal of Management and Science (ALQIMAH), 2018, Vol. 4, Issue 1, 1-15.

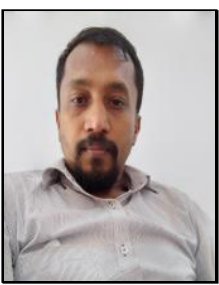

Ushan I. Peiris was born in Panadura, Sri Lanka, on $24^{\text {th }}$ August 1980 and obtained the first degree, B.Sc. Honors in Financial Management with a Second Class Upper Division from the Sabaragamuwa University of Sri Lanka in 2006. He has completed MSc. in Financial Mathematics at the University of Moratuwa and his doctoral of philosophy $(\mathrm{PhD})$ in Economics from Universiti Putra Malaysia. Currently, he is working as a Senior Lecturer at the Department of Accountancy and Finance, Faculty of Management Studies, Sabaragamuwa University of Sri Lanka. He has carried out several pieces of research and publication in different areas of economics and finance, such as Trade Integration, Monetary Integration, Stock Market volatility \& integration, and Foreign Direct Investment. 